\title{
Serious board games: modding existing games for collaborative ideation processes
}

\author{
Micael Sousa ${ }^{1}$ \\ ${ }^{1}$ University of Coimbra, Department of Civil Engineering, CITTA \\ micaelssousa@gmail.com
}

\section{Abstract}

Modern board games are booming, exploring new design elements, and providing dynamics that can support unique experiences. Serious game approaches can benefit from these insights and novelty. With the appropriate adaptation, modern board games may become flexible and cheaper ways to use and prototype serious games. Exploring these games and player engagement can support digital game design. Digital game designers may learn from modern board games to playtest player engagement and build prototypes for their serious games. This paper describes an experience with several adapted modern board games aiming to create a "Light Collaborative Ideation Process", supported by the "Engagement Design" model and "The big five personality traits". The game session objectives concerned fostering collaboration and ideation among participants in an informal meeting. The session successfully supported the potential of using modern board games, although showing the limitations and future developments required to benefit from the modding approach.

Keywords: Board games, Serious games, Collaboration, Soft Skills.

\section{Introduction}

Designing Serious Games (SG) is not an easy task [1], [2], especially when there are few time and resources available to allocate to their development. Profiting from existing games is an option [3]. Simple adaptations of well-established games can achieve predefined objectives while maintaining player engagement [4]. However, the possibility to transform entertainment games into SG demand proper systematization. Can it be done in fast gaming sessions (RQ1)? Without knowing the players' profiles (RQ2)? Will these findings related to modern board games be useful for digital SG development (RQ3)?

This paper describes an experimental dynamic after a meeting to synchronize and establish a common agenda for future activities. The experiment consisted of a sequence of modern board games, played with and without adaptations, to promote communication and co-creation for collaborative work. The games were introduced to establish empathy among participants that never meet before or did not have close relationships. The game facilitator selected and adapted four games to create a progressive dynamic intended to establish collaboration. The experiment invited players to focus on the priorities for the future common agenda. The games were fast, aiming to engage all the participants, considering their different player profiles. The experiment implemented a game-based "Light Collaborative Process for Ideation" (LCPI).

The established gameplay allowed an immediate debriefing with the participants after each game. The participants filled pre-tests and post-tests inquiries to record their global experiences, as well as inquires that focused on soft skills they explored during each different game, their own, and what they thought other players also experienced. Data collection, from the inquiries, was crossed with The big five personality traits [5] and the 
Engagement Design model [6] to confirm if the selected games fitted or not the three main typologies of players/users, as well as if they achieved the objectives of the SG approach. The facilitator used modern board games [7], [8], adapting them to the SG objectives and to player profiles [6]. This option was intended to produce a flexible approach to overcome the difficulties of dealing with different player profiles when using SG [2].

The adopted method followed SG approaches, as it departed from minor adaptations of entertainment games that would be played and debriefed to achieve serious purposes. Lowering the complexity of the original games was intended to allow instant playability. The provided game experiences should be fun for participants and serious by addressing predefined objectives [1], [9]. Gameplay should enrich the discussion and generate information beyond the formal meeting, helping participants and the meeting organizers to collaborate in future projects.

After the introduction, in section 2, we approach the concept of modding entertainment board games into SG, addressing the session objectives, personality traits, and player profiles. Section 3 presents the methodology for the practical game experiment. Section 4 delivers data collections, observations, and results. Discussion, conclusion, and limitations and future work are presented after.

\section{Modding board games to be serious games}

\subsection{Participation and collaboration}

The Participative Design (PD) methodologies, where small groups of people do co-creative tasks [10] and solve problems [11], following also the influences of collaboration currently seen in Design Thinking (DT) processes as collective ideation [12], supported the game sequence established for the experiment. These groups, working in collaborative ways, can produce outputs, solutions, and new ideas through consensus building. As an indirect result, a resilient participative community able to solve common future problems also can emerge [13], developing accepted ideas and solutions for collective problems [14].

Among the prerequisites for collaborative planning, there is the need to create a common language [15], losing the power relations that undermine relations, and establishing equality in participation [16], shared decision [17]. Dealing with nonlinearity approaches in collaborative development allows flexibilization to address complexity [13]. To achieve these collaborative approaches active facilitation is mandatory [18].

Because games are rule-bounded arenas of testing, where players solve problems individually and collectively [19], games can be tools to establish collaboration in multiplayer activities. The use of multiplayer analog games deepens, even more, the dynamics for collaboration because these game systems demand players conscientious agreement and involvement to function [20]-[22]. The materiality of these games also improves the tangibility and empathy between players [23].

\subsection{Start modding board games}

Board games can be used directly or adapted to be SG [3]. It depends upon many factors such as the player profiles [6], the context, the previous experiences, and many other conditions [24], but the debriefing process is essential to help players achieve the games' serious objectives [25]. Considering the variety and complexity games may have, the need for adaptation and establish a profound debriefing process can vary. Ignoring the need for debriefing may undermine the effects of the SG [2].

There are many available board games to choose from. We propose to use Board Game Geek (BGG) (www.boardgamegeek.com) database because of its acceptability in the board game community [26], [27]. BGG allows selecting the most high-ranked games related to 
mechanisms and other typologies like the number of players, complexity, and gameplay duration.

The presence of a facilitator in SG processes, done with existing analog games, is mandatory [28], [29], also considering the need to explain the game rules progressively [26], [30].

\subsection{From personality traits and facets to skills and player profiles}

The big five personality traits and their multiple facets [5], considering ten possible feelings experienced during gameplay, was the base to identify soft skills experienced during gameplay (see Table 3). These feelings and skills can be useful to explore the kind of experiences players have in games and how it contributes to the SG objectives.

Although there is a tendency to seek ways to explore soft skills, it is hard to provide a definition and a list of them, as Schulz [31] noticed, because it depends mainly on the context of analysis. Schulz [31] provided some examples of common soft skills: Communication skills; Critical and structured thinking; Problem-solving skills; Creativity; Teamwork capability; Negotiating skills; Self-management; Time management; Conflict management; Cultural awareness; Common knowledge; Responsibility; Etiquette and good manners; Courtesy; Self-esteem; Sociability; Integrity/Honesty; Empathy.

Although many soft skills are transversal and hard to define, the proposed relationship of "The big five personality factors" facets and feelings expressed during gameplay can help. Table 1 expresses those relations for the present case study.

Table 1. Personality factors, facets and proposed feeling and soft skills.

\begin{tabular}{|c|c|c|c|}
\hline $\begin{array}{c}\text { The Big Five } \\
\text { Personality Factors }\end{array}$ & Facets & $\begin{array}{c}\begin{array}{c}\text { Proposed experience } \\
\text { feeling during } \\
\text { gameplay }\end{array} \\
\end{array}$ & $\begin{array}{c}\text { Proposed relations to } \\
\text { Soft Skills }\end{array}$ \\
\hline \multirow{2}{*}{ Consciousness } & \multirow{2}{*}{$\begin{array}{c}\text { Competence (Efficient) and } \\
\text { achievement. }\end{array}$} & $\begin{array}{l}\text { Efficiency (success in } \\
\text { Problem solving). }\end{array}$ & $\begin{array}{l}\text { Critical and structured } \\
\text { thinking. }\end{array}$ \\
\hline & & $\begin{array}{l}\text { Competence (skills for } \\
\text { problem-solving). }\end{array}$ & $\begin{array}{l}\text { Self-management. } \\
\text { Time management. }\end{array}$ \\
\hline \multirow{2}{*}{$\begin{array}{l}\text { Openness to } \\
\text { experience }\end{array}$} & Fantasy (Imagination). & $\begin{array}{l}\text { Imagination } \\
\text { (Creativity). }\end{array}$ & \multirow{2}{*}{$\begin{array}{l}\text { Communication Skills. } \\
\text { Creativity. } \\
\text { Cultural awareness. } \\
\text { Sociability. }\end{array}$} \\
\hline & Curiosity & Curiosity & \\
\hline Extraversion & $\begin{array}{l}\text { Excitement seeking and } \\
\text { positive emotions }\end{array}$ & Excitement & $\begin{array}{l}\text { Communication Skills } \\
\text { Sociability } \\
\text { Conflict management }\end{array}$ \\
\hline \multirow{3}{*}{ Agreeableness } & Trust & Trust & \multirow{3}{*}{$\begin{array}{l}\text { Communication Skills } \\
\text { Teamwork capability } \\
\text { Negotiating skills } \\
\text { Courtesy } \\
\text { Sociability } \\
\text { Conflict management }\end{array}$} \\
\hline & Altruism & Altruism & \\
\hline & $\begin{array}{c}\text { Compliance, modesty, and } \\
\text { tenderness }\end{array}$ & Empathy & \\
\hline \multirow{2}{*}{$\begin{array}{c}\text { Neuroticism/ } \\
\text { Emotional stability }\end{array}$} & Anxiety & Anxiety & \multirow{2}{*}{$\begin{array}{l}\text { Self-management } \\
\text { Conflict management }\end{array}$} \\
\hline & Vulnerability to stress & Stress & \\
\hline
\end{tabular}

Table 1 provided the framework for the Game Inquiry (GI) players filled after each play (the game inquiry results are expressed in Table 5, 6, and 7). Through GI players mark their feelings to a five-degree Likert scale, which latter can be related to the streams and users [6]. Players evaluated their feelings (p), which established and group average of personal feelings (Mp), and what they think other players felt (o) during gameplay, resulting in average scores for the group (Mo). Zagalo [6] proposes the Engagement Design model for design interaction motivations that can be applied to game development (see Figure 1). This framework can also help adjust and choose games to engage users in SG approaches. 

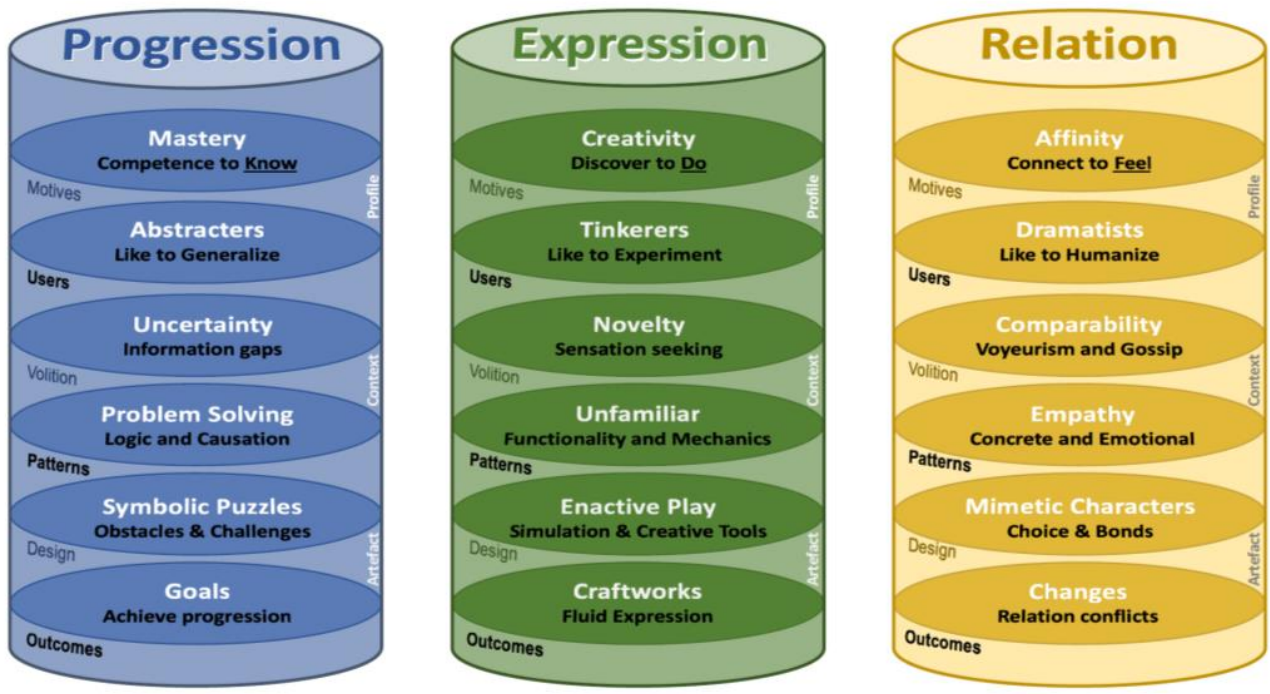

Figure 1. Engagement Design model: Designing for Interaction Motivations [6]

\section{Methodology}

After the formal meeting, the game experience lasted one hour and a half. The facilitator selected several board games expecting to deliver enjoyable game experiences to as many players as possible. The games were medium and low complexity (lower than 2.00 where the maximum is 5 , see Table 1), able to be playable within the available time. The selected games were high-ranked games at BGG (higher than 3.000 rank). They were party games with mechanisms to foster creativity and cooperative games to engage players in collective endeavors.

\subsection{Selecting and modding games for the experience}

The facilitator adapted the selected games to fit SG purposes for the meeting. To understand the adaptations, Table 2 resumes the original games played during the experiment as their complexity level according to BGG databases. The game adaptations are, therefore, expressed in Table 3. BGG game's complexity level is determined by users, according to a system of Bayesian averages. The BGG complexity varies from 1 to 5 . A game classified between 1 and 2 is of low complexity, suited for fast learning and playing.

Table 2. Summary of the unchanged games used in the experience and their complexity according to $B G G$.

\begin{tabular}{c|l|c}
\hline Name of the game & \multicolumn{1}{|c}{ Game description } & Complexity (1 to 5) \\
\hline Dixit [32] & $\begin{array}{l}\text { Players share oral narratives inspired } \\
\text { by the surrealistic colored drawings } \\
\text { of the cards. }\end{array}$ & 1.23 \\
\hline Team3 (T3) [33] & $\begin{array}{l}\text { Two teams try to be the fastest to } \\
\text { complete a 3D model with different } \\
\text { colored and shaped pieces. Each } \\
\text { team is composed of three players, } \\
\text { each player with a different role. The } \\
\text { first player can read the goal } \\
\text { blueprint and communicate by }\end{array}$ & \\
\hline
\end{tabular}




\begin{tabular}{|c|c|c|}
\hline & $\begin{array}{l}\text { gestures to the second player. The } \\
\text { second player can see the gestures } \\
\text { and talk instructions to the third } \\
\text { player. The third player must close } \\
\text { his eyes and listen to the second } \\
\text { player while it tries to do the goal by } \\
\text { combining the plastic pieces. }\end{array}$ & \\
\hline Magic Maze (MM) [34] & $\begin{array}{l}\text { A cooperative game where players } \\
\text { control a group of four adventures. } \\
\text { The objective is to get the right } \\
\text { weapon for each adventurer and } \\
\text { escape the maze. Players cannot talk } \\
\text { during the game. Players can only } \\
\text { use a pawn to signal the attention of } \\
\text { another player. Each player can do } \\
\text { one or two movement actions (north, } \\
\text { south, east, and west), discovering } \\
\text { and add maze tiles, using portals and } \\
\text { ladders. The red hourglass action in } \\
\text { the board allows players to flip the } \\
\text { hourglass that controls the time to } \\
\text { escape and to speak during the } \\
\text { process. It is a real-time game with } \\
\text { no predefined sequence of actions. }\end{array}$ & 1.73 \\
\hline Telestrations (TL) [35] & $\begin{array}{l}\text { Players write a word in their } \\
\text { notebooks. After writing, players } \\
\text { draw pictures representing that word } \\
\text { on the next page. Then the process is } \\
\text { repeated. Players pass the notebooks } \\
\text { among other players in sequence, } \\
\text { allowing the next player to see only } \\
\text { the previous page. This notebook } \\
\text { passing creates sequences of draws } \\
\text { and words, resulting from creative } \\
\text { and interpretative interactions. It } \\
\text { builds a sequence interaction without } \\
\text { complete information. }\end{array}$ & 1.09 \\
\hline
\end{tabular}

Following these insights, the game experiment intended to establish a Light Collaborative Process for Ideation (LCPI) through three steps (see Table 3).

Table 3. Assumed player skills in a "Light Collaborative Process for Ideation" (LCPI) with adapted games.

\begin{tabular}{c|c|c}
\hline $\begin{array}{c}\text { LCPI steeps } \\
\text { Game }\end{array}$ & \multicolumn{1}{|c}{ Objectives } & \multicolumn{1}{c}{ Adaptation } \\
\hline Step (1) & $\begin{array}{l}\text { Breaking the Ice" and sharing } \\
\text { controlled personal information by } \\
\text { players. Dynamic intended for } \\
\text { introducing players to each other. } \\
\text { Allows creating some starting } \\
\text { common knowledge that will help to } \\
\text { establish common languages [15]. }\end{array}$ & $\begin{array}{l}\text { Display random Dixit cards } \\
\text { faced up over a table. The } \\
\text { number of cards should be at } \\
\text { least ten times the number of } \\
\text { players. Without giving any } \\
\text { information to players, they } \\
\text { pick a card, and, after all the } \\
\text { players have their cards, they } \\
\text { present themselves to the } \\
\text { group based on the card they } \\
\text { picked. }\end{array}$ \\
\hline $\begin{array}{c}\text { Step (2) } \\
\text { Team3 }\end{array}$ & $\begin{array}{l}\text { General collaborative processes } \\
\text { where players need to use their } \\
\text { Step (2) }\end{array}$ & $\begin{array}{c}\text { No adaptation is needed, just } \\
\text { playing the easiest version of } \\
\text { the game. }\end{array}$ \\
\hline
\end{tabular}




\begin{tabular}{|c|c|c|}
\hline Magic Maze & $\begin{array}{l}\text { for promoting equality [16] and } \\
\text { sharing decisions to achieve } \\
\text { objectives [14]. }\end{array}$ & \\
\hline $\begin{array}{c}\text { Step (3) } \\
\text { Telestrations }\end{array}$ & $\begin{array}{l}\text { Informal co-creation process through } \\
\text { linearity and non-linearity interactive } \\
\text { sequences [13]. This co-creation } \\
\text { produces new ideas for players' } \\
\text { common problems and challenges } \\
\text { [14], considering multiples } \\
\text { expressions through drawing and } \\
\text { writing, following personal } \\
\text { interpretations that form a collective } \\
\text { narrative. }\end{array}$ & $\begin{array}{l}\text { Do not use the cards in the } \\
\text { game. Instruct the players to } \\
\text { choose a word representing the } \\
\text { priority for collective projects } \\
\text { to develop in the future. } \\
\text { Players must not discuss their } \\
\text { selected priorities while the } \\
\text { game is happening. Then, after } \\
\text { the end game, each player } \\
\text { presents his notebook so the } \\
\text { discussion may occur freely. }\end{array}$ \\
\hline
\end{tabular}

After each play, the facilitator conducts a debriefing debate [32], done informally, inviting players to discuss their behavior and analyze the group gameplay. The players answer a pre-test and a post-test done to record player characteristics, game performance, game experience, game satisfaction, and game serious objectives, following the recommendations from Mayer et al. [24]. Another inquiry intended to record each feeling players experienced in each game was defined (GI).

The selected games (see Table 2), and their adaptations (see Table 3), created a sequence where players engaged in collaboration and ideation. But, as Zagalo [6] notices, there can be at least three types of different users engaged in games, all for different reasons: the abstracters that like to generalize, deal with uncertainty, and do problem-solving; the tinkerers that like to experiment, the novelty and the creativity, and; the dramatics that like the humanize, establishing empathy among other players. Ignoring these different player profiles and what engages players may undermine the success of choosing and adapting games. Choosing games to engage as many users as possible is beneficial. The three streams from the engagement design model deliver a framework to support these decisions.

\subsection{Games targeted to user profiles and $S G$ objectives}

The Dixit cards were useful to help "break the ice", supporting players' presentation. But the storytelling presentations had no special rules or objectives and scoring system. It was just a dynamic and not a game. Because of this, players did not fill the GI for this game. However, Dixit storytelling presentations were considered in Table 4 as an LCPI step.

Excitement and stress emotions were not considered in the experiment analysis, because they can occur in every game as a positive or negative reaction to the engagement preferences. All the played games had time restrictions intended to create fast games, providing stress to players.

Table 4. LCPI steps and games related to player skills.

\begin{tabular}{c|l}
\hline $\begin{array}{c}\text { LCPI steps } \\
\text { Game }\end{array}$ & \multicolumn{1}{c}{ Expected player skills in games } \\
\hline Step (1) \\
Dixit & $\begin{array}{l}\text { Efficiency (communication). } \\
\text { Curiosity (choosing and describing the cards). } \\
\text { Imagination (expression trough personal. } \\
\text { storytelling). } \\
\text { Empathy (expression trough personal } \\
\text { storytelling). }\end{array}$ \\
\hline Step (2) & $\begin{array}{l}\text { Efficiency (problem-solving). } \\
\text { Empathy (collective attention). }\end{array}$ \\
& $\begin{array}{l}\text { Trust (other players' attention). } \\
\text { Anxiety management (time management and } \\
\text { communicating priorities to other players). }\end{array}$ \\
\hline
\end{tabular}




\begin{tabular}{|c|c|}
\hline & $\begin{array}{l}\text { Competence (problem-solving). } \\
\text { Altruism (adapting to other players' performance). } \\
\text { Stress management (time management and } \\
\text { communicating priorities to other players). }\end{array}$ \\
\hline $\begin{array}{c}\text { Step (2) } \\
\text { Magic Maze }\end{array}$ & $\begin{array}{l}\text { Efficiency (problem-solving). } \\
\text { Empathy (collective attention). } \\
\text { Trust (other players' attention). } \\
\text { Anxiety management (time management and } \\
\text { communicating priorities to other players). } \\
\text { Competence (problem-solving). } \\
\text { Altruism (adapting to other players' performance) } \\
\text { Stress management (time management and } \\
\text { communicating priorities to other players). }\end{array}$ \\
\hline $\begin{array}{c}\text { Step (3) } \\
\text { Telestrations }\end{array}$ & $\begin{array}{l}\text { Efficiency (communication and interpretation). } \\
\text { Imagination (idea proposal and interpretation). } \\
\text { Empathy (interpretation of the draw and words). } \\
\text { Trust (player do not break the ideas). } \\
\text { Anxiety (bad drawing and misspelling). } \\
\text { Competence (drawing and guessing). } \\
\text { Curiosity (interpretation of the words and draws). } \\
\text { Altruism (adapting the message to other players). } \\
\text { Stress management (Time management, bad } \\
\text { drawing, and misspelling). }\end{array}$ \\
\hline
\end{tabular}

Figure 2 represents a matrix and scheme where each game relates to at least two of the three columns/streams of the Engagement Design model (and its player profiles). These relations depart from the proposed dominant feelings players can experience during gameplay were described in Tables 3 and 4 . Through the following scheme (see Figure 2) is possible to establish the LCPI, supported by the Engagement Design model [6] and the soft skill [31] related to The big five personality traits [5] in a pragmatic way.

\begin{tabular}{|c|c|c|c|c|}
\hline 己े & Games & Progression & Expression & Relation \\
\hline 1 & Dixit & & a & 口 \\
\hline 2 & Team3 & a & & a \\
\hline 2 & Magic Maze & $\square$ & & $\square$ \\
\hline \multirow[t]{3}{*}{3} & Telestrations & & 口 & 四 \\
\hline & & $\nabla$ & $\nabla$ & $\nabla$ \\
\hline & Most fit for: & Abstracters & Tinkerers & Dramatists \\
\hline \multicolumn{2}{|c|}{$\begin{array}{r}\text { Dominant expected Feelings } \\
\text { during gameplay }\end{array}$} & $\begin{array}{c}\text { Efficiency; } \\
\text { Competence. }\end{array}$ & $\begin{array}{l}\text { Imagination; } \\
\text { Curiosity. }\end{array}$ & $\begin{array}{l}\text { Empathy; Trust; } \\
\text { Altruism. }\end{array}$ \\
\hline
\end{tabular}

Figure 2. Engagement Design model for the selected games considering the types of users and expected feelings during gameplay.

In Team3 (T3) players must master how the different roles communicate to complete the puzzles. The game demands communicative expression and creativity, although the most notorious expected skills are problem-solving and empathy among players due to all the communications restrictions.

In Magic Maze (MM) players need to manage the movement efficiently, combining all their allowed actions. Players can talk freely during the hourglass spinning and before the game. The continuous novelty is introduced in the game as the maze unfolds and changes.

Telestrations (TL) gives freedom and empowers players. They can pick the first word and interpret the following words and draws. It delivers creative expression, graphic communication, and interpretation challenge exercises.

All games foster relations among players due to their collaborative gameplay nature and need for collective agreement to activate the game system. 


\section{Observations and results}

\subsection{The general meeting}

Twelve participants attended this formal meeting, with most of the attendants meeting each other there for the first time. The formal meeting had a duration of two hours. It started with personal presentations, followed by each participant sharing information about their associations or projects. There was a collective agreement that coordinating a common agenda would bring collective benefits to all, although it was not evident what to do and when. Nearly half of the participants did not attend the meeting until the end, and only six stayed for the game dynamic ( $n=6)$, planned to occur after the formal meeting. The game experiment had a total duration of one hour and a half. The meeting happened late in the afternoon, and many participants claimed they had other appointments to justify leaving the meeting during the formal discussion before the games.

\subsection{Game inquiries results}

Because all the inquiries were anonymous, which impossibilities singular players analysis, only average results (M) supported this experience. The Mp relates to self-evaluation, and Mo relates to the perception of other players' feelings during gameplay with the GI. The difference between the $\mathrm{Mp}$ and Mo is the average perception variation between selfevaluation and evaluating other players, which is useful to address general empathy during collaboration. The standard deviation (SD) considers the differences between players' evaluations, which can provide insights about the different profiles and how players reacted uniquely to the tested games.

Tables 5, 6, and 7 express players' experiences after playing the games (Team3, Magic Maze, and Telestrations). In Table 5 (Team3) curiosity was the personal feeling with the highest average score $(\mathrm{Mp}=4.00)$, although players attributed the higher feeling perception about other players to empathy $(\mathrm{Mo}=4.17)$. The highest personal deviation was in trust $(\mathrm{SDp}=1.21)$, which is understandable because it was the first game. Competence had the same self-evaluation as the other players' feelings $(\mathrm{Mp}=\mathrm{Mo}=3.50)$, although the $\mathrm{SD}$ varied to some extent $(\mathrm{SDp}=1.05$ and $\mathrm{SDo}=0.84$ ). This tendency of considering other players' performance better them their own was common in all games.

Table 5. Reported feelings by players during Team3.

\begin{tabular}{c|c|c|c|c|c}
\hline $\begin{array}{c}\text { Feelings/ } \\
\text { Behavior }\end{array}$ & Mp & SDp & Mo & SDo & Mp-Mo \\
\hline Efficiency & 3.00 & 1.10 & 3.17 & 0.75 & -0.17 \\
\hline Imagination & 3.67 & 1.03 & 3.67 & 0.82 & 0.00 \\
\hline Empathy & 3.67 & 1.03 & 4.17 & 0.41 & -0.50 \\
\hline Trust & 3.33 & 1.21 & 4.00 & 0.63 & -0.67 \\
\hline Anxiety & 2.50 & 1.05 & 3.00 & 0.63 & -0.50 \\
\hline Competence & 3.50 & 1.05 & 3.50 & 0.84 & 0.00 \\
\hline Curiosity & 4.00 & 0.63 & 3.83 & 0.41 & 0.17 \\
\hline Excitement & 3.50 & 0.55 & 3.50 & 0.55 & 0.00 \\
\hline Altruism & 3.83 & 0.41 & 4.00 & 0.00 & -0.17 \\
\hline Stress & 2.00 & 0.63 & 2.17 & 0.75 & -0.17 \\
\hline
\end{tabular}

In Table 6 (Magic Maze) excitement was the highest feeling players expressed in their perception $(\mathrm{Mp}=4.33)$, something also evident when considering other players' evaluation 
$(\mathrm{Mo}=4.17)$. Empathy also had the highest score by other players' perceptions $(\mathrm{Mo}=4.17)$. Altruism felt by other players was evaluated with the same grade by all players $(\mathrm{Mp}=4.00$ and $\mathrm{SD}=0.00)$.

Table 6. Reported feelings by players during Magic Maze.

\begin{tabular}{c|c|c|c|c|c}
\hline $\begin{array}{c}\text { Feelings/ } \\
\text { Behavior }\end{array}$ & Mp & SDp & Mo & SDo & Mp-Mo \\
\hline Efficiency & 3.67 & 0.52 & 3.83 & 0.41 & -0.17 \\
\hline Imagination & 3.33 & 1.03 & 3.83 & 0.75 & -0.50 \\
\hline Empathy & 4.00 & 0.89 & 4.17 & 0.41 & -0.17 \\
\hline Trust & 3.50 & 0.84 & 3.67 & 0.82 & -0.17 \\
\hline Anxiety & 3.67 & 1.21 & 3.50 & 0.84 & 0.17 \\
\hline Competence & 3.17 & 0.75 & 4.00 & 0.00 & -0.83 \\
\hline Curiosity & 4.17 & 0.98 & 3.83 & 0.75 & 0.33 \\
\hline Excitement & 4.33 & 0.82 & 4.17 & 0.75 & 0.17 \\
\hline Altruism & 3.67 & 0.52 & 4.00 & 0.00 & -0.33 \\
\hline Stress & 3.33 & 0.82 & 3.50 & 0.84 & -0.17 \\
\hline
\end{tabular}

In Table 7 (Telestrations) the highest expression from players' self-evaluation was curiosity $(\mathrm{Mp}=4.50$ and $\mathrm{SDp}=0.84)$ followed by imagination $(\mathrm{Mp}=4.33, \mathrm{SDp}=0.84)$. Imagination $(\mathrm{Mp}=4.33, \mathrm{SDp}=0.52)$ and curiosity $(\mathrm{Mo}=4.33, \mathrm{SDo}=0.82)$ were also the highest evaluation perception players attributed to the other players' expressions during gameplay.

Table 7. Average feelings by players during Telestrations.

\begin{tabular}{c|c|c|c|c|c}
\hline $\begin{array}{c}\text { Feelings/ } \\
\text { Behavior }\end{array}$ & Mp & SDp & Mo & SDo & Mp-Mo \\
\hline Efficiency & 3.67 & 0.52 & 3.83 & 0.75 & -0.17 \\
\hline Imagination & 4.33 & 0.82 & 4.33 & 0.52 & 0.00 \\
\hline Empathy & 3.83 & 0.75 & 4.33 & 0.52 & -0.50 \\
\hline Trust & 3.67 & 0.82 & 4.17 & 0.41 & -0.50 \\
\hline Anxiety & 2.83 & 1.60 & 2.67 & 1.37 & 0.17 \\
\hline Competence & 3.17 & 0.41 & 3.83 & 0.75 & -0.67 \\
\hline Curiosity & 4.50 & 0.84 & 4.33 & 0.82 & 0.17 \\
\hline Excitement & 3.50 & 0.55 & 4.00 & 0.89 & -0.50 \\
\hline Altruism & 4.00 & 0.63 & 3.50 & 0.55 & 0.50 \\
\hline Stress & 2.33 & 1.51 & 2.33 & 1.21 & 0.00 \\
\hline
\end{tabular}

In Table 8, the Average (M) and standard deviation (SD) obtained from the game inquiries should allow an easy direct comparison for the sequence of games. The results from the Mp-Mo express the maximum gap between them.

The game sequence reveals that the efficiency, trust, and curiosity raised from game to game in the self-evaluation (Mp) and the evaluation of the other players' perceptions (Mo). Other feelings variated greatly. Imagination and curiosity increased from game to game as expected because the last game (Telestrations) was the most adequate to foster creativity.

Considering both perspective evaluations ( $\mathrm{Mp}$ and $\mathrm{Mo}$ ), the reduction of imagination from Team 3 to Magic Maze and the increase in Telestrations evidence the expected reaction 
predicted in Figure 2. The efficiency increased from Team3 to Magic Maze and remained the same during Telestrations. The empathy increased from Team 3 to Magic Maze and then decreased in Telestrations, but only in the self-evaluation, while the perception of other players' behavior increased. The first two games demanded more collaboration among players, while the third was more prone to individual creativity. The anxiety had a peak during Magic Maze, understandable due to the communication and time restrictions. This anxiety seems to relate to excitement because the two feelings burst during Magic Maze.

Table 8 expresses the differences between average self (Mp) and average collective evaluations (Mo). Competence and altruism manifested the maximum difference of 0.83 between self-evaluation and collective behavior. These gaps may reveal the manifestation of abstracters and dramatists [6] expressing their feelings while playing the different games and noticing other players be different from them. Considering the tinkerers' users (see Figure 1) and their preferences [6] (see Figure 2), the difference did not seem so evident because the gap for imagination was 0.50 and curiosity only 0.17 .

Table 8. Average results about feeling during gameplay.

\begin{tabular}{|c|c|c|c|c|c|c|c|c|c|c|}
\hline \multirow{2}{*}{$\begin{array}{l}\text { Feelings/ } \\
\text { Behavior }\end{array}$} & \multicolumn{3}{|c|}{ Мp } & \multicolumn{3}{|c|}{ Mo } & \multicolumn{4}{|c|}{ Mp-Mo } \\
\hline & T3 & MM & $\mathbf{T L}$ & T3 & MM & TL & $\mathbf{T 3}$ & MM & $\mathbf{T L}$ & $\begin{array}{c}\text { Maximum } \\
\text { gap }\end{array}$ \\
\hline Efficie & 3.00 & & 3.67 & 3.17 & 83 & 3 & 7 & 7 & .17 & 0.00 \\
\hline $\mathrm{ma}$ & 3.67 & 3.33 & 4.33 & 3.67 & 3.83 & 4.33 & 0.00 & -0.50 & 0.00 & 0.50 \\
\hline Empa & 3.67 & 400 & 3.8 & 4.17 & 4.17 & 433 & -050 & 0.17 & 0.50 & 0.33 \\
\hline 1 & 3. & & & 4.00 & & & 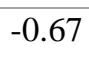 & -0.17 & -0.50 & 0.50 \\
\hline Anxiety & 2.50 & 3.07 & 2. & 0 & 80 & סI & 0 & 17 & 17 & .67 \\
\hline ompetence & 3.50 & 317 & 317 & 350 & 4.00 & 3.83 & 0.00 & -0.83 & -0.67 & 0.83 \\
\hline Curiosity & 4.0 & 417 & 4.50 & 3.83 & $5.0 J$ & 432 & 01 & 0.33 & 01 & 0 \\
\hline Excitement & 3.50 & 4.33 & 3.50 & 3.50 & 4.17 & 4.00 & 0.00 & 0.17 & -0.50 & 0.67 \\
\hline Altruism & 3.83 & 3.67 & 4.00 & 4.00 & 4.00 & 3.50 & -0.17 & -0.33 & 0.50 & 0.83 \\
\hline Stress & 2,00 & 3.33 & 2.33 & 2.17 & 3.50 & 2.33 & -0.17 & -0.17 & 0.00 & 0.17 \\
\hline
\end{tabular}

After each game, players also wrote the first words that come to their mind relating to the previous gameplay. The collected words were analyzed through the grounded theory [33] and organized in Table 9. Some players did not write as many words as others, which produced more data in some games than others (see Table 9).

Table 9. First words players wrote after each game to describe gameplay

\begin{tabular}{|c|c|c|c|c|c|c|c|c|c|}
\hline Game & 突 & 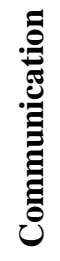 & 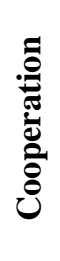 & 芑 & 㺼 & $\underset{\Xi}{\Xi}$ & 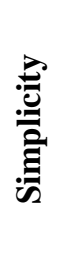 & $\frac{\bar{\nabla}}{\bar{d}}$ & Еี \\
\hline Team3 & 0 & 3 & 3 & 1 & 0 & 2 & 0 & 4 & 1 \\
\hline Magic Maze & 1 & 2 & 5 & 1 & 0 & 1 & 0 & 4 & 0 \\
\hline Telestrations & 6 & 1 & 0 & 0 & 1 & 0 & 2 & 1 & 0 \\
\hline
\end{tabular}

Skill, communication, and tension (relating to competence and progression) emerged in Team3. Cooperation and skill emerged in Magic Maze more than other games, despite all being collaborative. On the other hand, creativity appeared more in Telestrations as 
expected due to the freedom to draw and interpret drawings. Players highlighted the simplicity of Telestrations, which confirms the low complexity classification from BGG (see Table 2).

\subsection{Game pretests and posttests results}

The pre-test and post-test were useful to collect more data about the participants. The game habits, considering all game types, are considered not high. Only one player admitted playing at least once per day. Three played at least once per week, two once per month, and the last one reported playing less than once per month (at least once per year). These game habits lead as concluding that participants were not very interested in games. However, when asked if games are fun, the average value for the responses was $M=4.33$ with $\mathrm{SD}=0.47$. The low game habits may explain why the average evaluation increased to $\mathrm{M}=4.50$ with $\mathrm{SD}=0.50$ after playing the games (see Table 10). The result for the global engagement was high $(\mathrm{M}=4.67, \mathrm{SD}=0.47)$, with a low level of frustration $(\mathrm{M}=2.33$, $\mathrm{SD}=1.20)$ and medium level of anxiety $(\mathrm{M}=3.17, \mathrm{SD}=1.50)$, despite the considerable variation in player interpretations. The challenge level $(\mathrm{M}=4.50, \mathrm{SD}=0.50)$ was high, a source of enjoyment when considering the other feelings. The surprise factor was not as high as expected $(\mathrm{M}=4.00, \mathrm{SD}=1.82)$ considering low game habits. The feelings/behaviors identified in Table 10 are related to the The Big 5 personality traits (see Table 1).

Table 10. Post-test results

\begin{tabular}{c|c|c|c|c|c|c|c}
\hline $\begin{array}{c}\text { Feelings/behavior } \\
\text { after the } \\
\begin{array}{c}\text { sequence of } \\
\text { games }\end{array}\end{array}$ & $\mathbf{1}$ & $\mathbf{2}$ & $\mathbf{3}$ & $\mathbf{4}$ & $\mathbf{5}$ & M & SD \\
\cline { 2 - 7 } & 0 & 0 & 0 & 3 & 3 & 4.50 & 0.50 \\
\hline Fun & 0 & 1 & 2 & 1 & 2 & 3.67 & 1.39 \\
\hline Difficulty & 0 & 0 & 0 & 2 & 4 & 4.67 & 0.47 \\
\hline Engagement & 0 & 0 & 0 & 3 & 3 & 4.50 & 0.50 \\
\hline Challenge & 0 & 2 & 2 & 1 & 1 & 3.17 & 1.50 \\
\hline Anxiety & 0 & 0 & 0 & 2 & 4 & 4.67 & 0.47 \\
\hline Adaptation & 0 & 0 & 2 & 2 & 2 & 4.00 & 0.82 \\
\hline Surprise & 1 & 3 & 1 & 1 & 0 & 2.33 & 1.20 \\
\hline Frustration & & & & & & &
\end{tabular}

When comparing the motivation before and after the games, the average evaluation increased from $M=4.33$ to $M=4.50$. The correlation between the answers to the question "if games were fun" (see Table 11) was perfect.

Considering the objectives of establishing the conditions for future collaboration projects, players classified the experience as a success, with $\mathrm{M}=4.67$ ( $\mathrm{SD}=0.47$ ). When asked if they would play these games in the future for fun, the average answer was $M=4.50$ $(\mathrm{SD}=0.5)$.

Table 11 also expresses post-tests results, where players manifested a global evaluation about the fun and excitement higher than each GI. Although the anxiety levels were higher at the end of the experience, they were lower than in Magic Maze. These high anxiety and enjoyment are examples of paradoxical feelings expressed in games. 
Table 11. Comparison of self-evaluation from GI and the post-test

\begin{tabular}{c|c|c|c|c}
\hline \multirow{2}{*}{$\begin{array}{c}\text { Feelings/ } \\
\text { Behavior }\end{array}$} & \multicolumn{3}{|c|}{ Mp (GI) } & $\begin{array}{c}\text { End of the } \\
\text { experiment (M) }\end{array}$ \\
\cline { 2 - 4 } Anxiety & 2.50 & MM & TL & 3.17 \\
\hline Fun/Excitement & 3.50 & 3.67 & 2.83 & 4.50 \\
\hline
\end{tabular}

\subsection{Game Observations}

Players grasped every game with only one explanation, even though they did not know the games previously. Only minor doubts occurred during gameplay, easily explained by the facilitator. It was notorious that some players were more engaged in some games than others. The laughing, commenting, and discussing gameplay varied from game to game and from player to player. At the start of the games, two players said they need to leave after the first game, but they continued to play until the end.

The personal presentation, using Dixit cards, instantly changed the mood in the room. Fun comments and smiley interactions between participants emerged. The contrast between the debate done in the previous meeting was notorious. In Team3, both teams ( 3 players each) managed to finish the objective almost at the same time, in less than 15 minutes. Although being a more complex and demanding game, players acknowledged Magic Maze in a fast way. By playing just one time, players were very close to fulfilling the game goal. One of the players, when the hourglass flipped, assumed leadership. He defined a collective plan to fulfill the goals. All players participated in this fast strategy debate. During the Telestrations game, there were convergence and divergence in the notebooks. Concepts like "communication", "Trust", "collaboration", "ideas", "leadership", "team" and "union" emerged from gameplay as priorities to achieve the objectives of the previous meeting.

After the game session, the facilitator conducted a fast debrief for 15 minutes. Players highlight their surprise and how the games generated empathy and collaboration. Players stated that tensions and difficulties mastering the games did not affect engagement. During the debriefing, players talked with more energy and enthusiasm than during the previous meeting. They were curious to try more games and game approaches to foster creativity and collaboration. Players identified several keywords related to cooperation (similar to Table 9).

\section{Discussion}

Players believed the game session achieved the session's objectives of fostering future collaborations $(\mathrm{M}=4.67)$. They stated the games to be enjoyable because they said they would play them in the future just for fun $(\mathrm{M}=4.5)$. The results from the Telestrations notebooks reinforced this perception. Without any preparation, players identified in the notebooks key concepts to establish collaborative approaches to the common objective. The final debate, during the debriefing, reinforced these perceptions.

The experiment established some relationships to soft skills expressed during the games, although they were, undoubtedly, difficult to analyze. Despite these difficulties, Team3 and Magic Maze obtained high scores in efficiency and competence as expected, establishing the relationship to abstracters and tinkerers. On the other end, Telestrations was the game where players expressed the most imagination and creativity, relating to tinkerers and dramatists. In all games, empathy, trust, and altruism maintained an $\mathrm{SD}=0.50$ or less, probably due to being collaborative games, even in Telestrations where the competitions departed from a process of co-creation.

These results show that the Engagement Design model can help to choose games to modify to be SG. The players support the initial claims that each game fits the three typologies of users (see Figure 1 and Table 9), at least in a general way according to their 
statements. BGG can support choosing games to modify into SG able to address soft skills like creativity and collaboration. But choosing sets of games that the different profiles can enjoy increases player engagement. The Engagement Design model seems to be a valid method to support these SG modding approaches. Facilitators benefit from the ability to engage all the different player profiles because they may ignore who will play the games.

Building SG from modding existent games can be a valuable resource for project managers, facilitators, community activators, and any agents who need fast tools to engage with first-time users or in continuous sessions that require progressive adaptation to users. Party games and other alike can be continuously adapted to approach multiple issues. Although this might seem easy, it is mandatory to know the games in detail, which skills they can explore, and balance the type, gender, and quantity of games to engage with users.

The increasing stress felt by players during the games can be explained by the hurry to leave the experience. Some attendants need to leave early. However, they continued playing until the end. These external influences affected game experiences, although some game systems deliver these feelings intentionally. This design feature is evident in Magic Maze, the game where the stress/anxiety generation occurred the most (see Table 8), despite one of the users referred to the tension it felt during Team 3 (see Table 9). Stress and anxiety during gameplay can be misleading because they can contribute to engagement in some games.

The experiment allows comparing the differences between personal and other players' perceptions. In multiplayer gameplay experiences, the interaction among players is constant, and it builds towards the potential of engagement. The highest gaps between personal and other players' perceptions happened in the feelings of competence and altruism. This example reveals how subjective they can be and can impact collaboration. Low altruistic group attitude and an unbalanced notion of competence among participants may undermine collaboration processes. Using games to evaluate and strengthen this feeling can help future SG, even as a prior exercise to a collaborative specific process not related to games.

Choosing low complexity games (see Table 2), supported by a permanent facilitator, proved efficient to engage first-time users without profound game habits. The LCPI was generic and flexible enough to help players relate to what was involved in a collaborative process. Players realized how other participants perceive the same experiences and can create different solutions to the same problems.

The leaving of many participants before the games must be stated as a potential problem. Participants might consider games as extra or unnecessary work. Introducing "icebreaking" games, like the use of Dixit [34] cards, can be a way to show participants the benefits of SG approaches, even without a scoring system.

We propose the following general scheme (Figure 3) to systemize the findings from the experiment. The proposed scheme can lead to future testing and comparing the proposed approach of the LCPI to other similar examples [4]. In it, the facilitator will define the SG objectives and available resources. The facilitator must identify contextual limitations to select a sample of games to modify and playtest. Playtesting might demand to restart the process if the SG objectives are not met. After assuring objectives are reachable, the facilitator can use the SG to deliver playable sessions. But the facilitator may realize that the objectives cannot be fully achieved with the available resources (i.e., time, numberer of players, and other context limitations), which may demand reconsidering the initial objectives to achieve through games. During the actual play, the analyses and evaluation of SG objectives are continuous.

Learning from the presented case study, we believe that the LCPI can be adapted to other goals and be a guidance framework to build SG approaches, done after modding modern board games. The SG processes departed from the LCPI are ready to use solutions or ways to support prototype building that game designers may use in their digital SG development. 


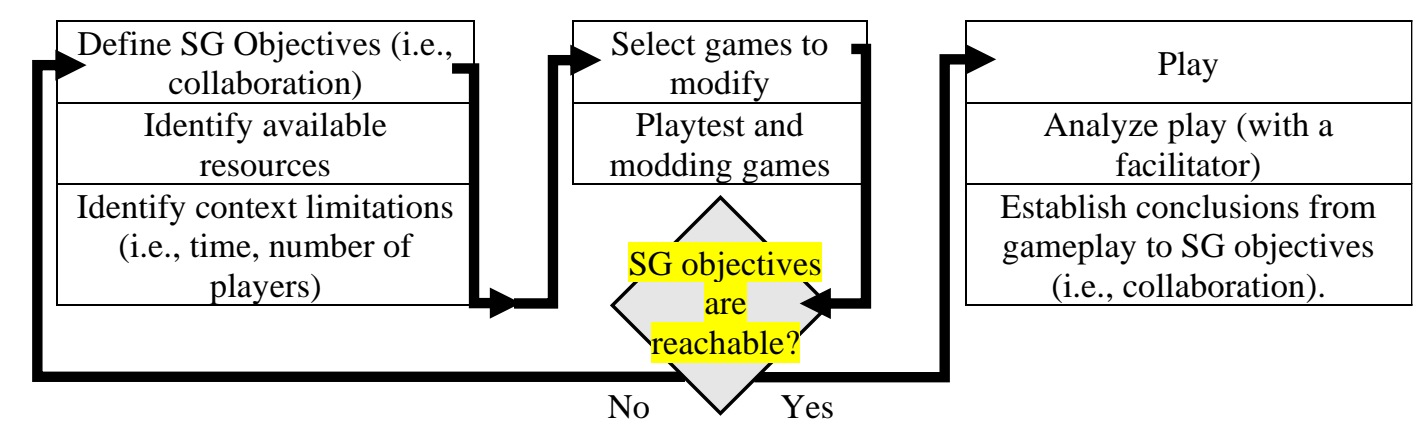

Figure 3. Scheme for modding board games to became $S G$ for the example of collaboration (appliable to the LCPI).

The previous scheme combines the polycentric game development approach with the multiple cycles of playtesting [37] with the goal-centered SG approaches. This scheme supports digital game design when it departs from analog game prototypes [38]. Understanding how players directly activate these analog game systems can help designers decide what to automatize in digital games.

\section{Conclusion}

The experience proved that modern board games are adaptable to foster collaborative engagement. Through the LCPI proposal, it is possible to say that players successfully identified some of the prerequisites for collaboration. By achieving this, players may be better prepared for future collaborative projects, although the game experience was brief and unable to test this accurately in other situations. Despite unknowing future player behaviors, the experiment proved that game usage can be a starting point to establish collaborative processes. The experiment highlighted the effects of different players' profiles and subjectivity in SG usages. That modding modern board games as SG deliver tools for soft skills development. The experiment demonstrated how, by doing game dynamics, a mood in a formal meeting changes without losing its serious intentions (RQ1).

The Engagement Design model was a valuable framework to choose games to engage with different players when facilitators have several available games but do not know the attendants (RQ2). Although players liked some games better than others, they all appreciated the game experience and how games addressed the meeting objectives. The big five traits approach was able to make relationships from expected player behavior and the streams of the Engagement Design model, easily measured by players' perceptions through the GI.

Profiting from existing games, which can be easily adapted, is valuable for fast and simple SG exercises (RQ1). The flexibility of modern board games to deliver fun and be engaging is valuable. When supported by adequate frameworks, they can become low-tech SG and support prototypes for digital SG development. Since many new modern game designs are continuously appearing, new opportunities are always available to modify and inspire new solutions.

Facilitators help to lower the game complexity, even when players have little experience with games. Facilitators also support players to establish the relationships between their personal and collective experiences to the SG objectives. The debriefing process is essential to guaranty that players achieve SG objectives.

The LCPI provided an example to systemize the modern board game modding to became SG. The LCPI highlighted the possibilities of exploring the design innovation and unique interactions of the modern board game for general SG design. We believe this 
systematic approach also brings new possibilities to future tests for digital serious games, at least for prototyping objectives (RQ3).

\section{Limitations and future work}

It was possible to collect data from two types of inquiries and formal observation. But the low number of participants $(n=6)$ cannot generate unquestionable results. Despite these limitations, the LCPI experience opens a path for future research and development, done with more players and games. Future research should enlarge the number of players and different played games. More data would establish clear patterns of behaviors. It could highlight the effect of each design element in the player experiences and the desirable serious outputs. Analyzing some dual feelings like stress and challenge must be crossed with other data sources, confirming if it is a positive or negative effect during gameplay (RQ2).

Upcoming experiences should benefit from comparing different types of games and other collaboration ideation processes without games. Introducing non-modern board games, digital games, and other game typologies could establish clear conclusions for SG usage. Board games can be explored in online video conversation platforms and as prototypes for digital games in future research (RQ3).

The experiment revealed how important it is to record each player's experience separately throughout all played games. This information would help to establish direct relationships between games and skills. As well as about what game elements each player profile appreciated the most. Because players may not express all their unconscious feelings through written questionnaires, filming gameplay, and use biometric data-gathering could bring valuable information to evaluate players' engagement.

There is also the need to deepen the debriefing process to collect information about players' behaviors for further analyses. This data would allow us to clearly understand the inquiries answers and the relationships with the SG objectives. The debriefing should follow a defined protocol, despite the obligation to be flexible to help the facilitator role.

\section{Acknowledgements}

The author would like to thank to Patrícia Oliveira for revising the text and give important feedback and to António Pais Antunes for supervising the author during the Ph.D.

\section{Funding}

This research was funded by "Fundação para a Ciência e a Tecnologia" (FCT), the Portuguese funding agency, for supporting this research, under the grant $\mathrm{PD} / \mathrm{BD} / 146491 / 2019$.

\section{References}

[1] R. Dörner, S. Göbel, W. Effelsberg, and J. Wiemeyer, Serious Games. Springer, 2016, doi: 10.1007/978-3-319-40612-1

[2] F. Bellotti et al., "Designing serious games for education: from pedagogical principles to game mechanisms," in Proceedings of the 5th European Conference on Games Based Learning, 2011, pp. 26-34.

[3] E. Castronova and I. Knowles, "Modding board games into serious games: The case of Climate Policy," Int. J. Serious Games, vol. 2, no. 3, pp. 41-62, 2015, doi: 
10.17083/ijsg.v2i3.77.

[4] M. Sousa, "Fast Brainstorm techniques with modern board games adaptations for daily uses in business and project managing," in Proceedings of the International Conference of Applied Business and Manage-ment (ICABM2020), 2020, pp. 508-524, [Online].

Available: https://icabm20.isag.pt/images/icabm2020/BookofProceedings.pdf.

[5] J. J. Heckman and T. Kautz, "Hard evidence on soft skills," Labour Econ., vol. 19, no. 4, pp. 451-464, 2012, doi: 10.1016/j.labeco.2012.05.014.

[6] N. Zagalo, Engagement Design: Designing for Interaction Motivations. Springer Nature, 2020, doi: 10.1007/978-3-030-37085-5.

[7] S. Woods, Eurogames: The Design, Culture and Play of Modern European Board Games. McFarland, Incorporated, Publishers, 2012.

[8] M. Sousa and E. Bernardo, "Back in the Game: modern board games," in Videogame Sciences and Arts, 2019, pp. 72-85, doi: 10.1007/978-3-030-37983-4_6.

[9] D. R. Michael and S. L. Chen, Serious games: Games that educate, train, and inform. Muska \\& Lipman/Premier-Trade, 2005.

[10] G. Sim, M. Horton, and J. C. Read, "Sensitizing: helping children design serious games for a surrogate population," in International Conference on Serious Games, Interaction, and Simulation, 2015, pp. 58-65, doi: 10.1007/978-3-319-29060-7_10.

[11] S. Paracha, L. Hall, K. Clawson, N. Mitsche, and F. Jamil, "Co-design with Children: Using Participatory Design for Design Thinking and Social and Emotional Learning," Open Educ. Stud., vol. 1, no. 1, pp. 267-280, 2019, doi: 10.1515/edu-2019-0021.

[12] J. Liedtka, "Perspective: Linking design thinking with innovation outcomes through cognitive bias reduction," J. Prod. Innov. Manag., vol. 32, no. 6, pp. 925-938, 2015, 10.1111/jpim.12163.

[13] J. E. Innes and D. E. Booher, Planning with complexity: An introduction to collaborative rationality for public policy. Routledge, 2018, doi: 10.4324/9781315147949.

[14] J. E. Innes and D. E. Booher, "Consensus building and complex adaptive systems: A framework for evaluating collaborative planning," J. Am. Plan. Assoc., vol. 65, no. 4, pp. 412-423, 1999, doi: 10.1080/01944369908976071.

[15] B. C. Crosby and J. M. Bryson, Leadership for the common good: Tackling public problems in a shared-power world, vol. 264. John Wiley I\& Sons, 2005.

[16] J. S. Dryzek, Discursive democracy: Politics, policy, and political science. Cambridge University Press, 1990, doi: 10.1017/9781139173810.

[17] S. S. Fainstein and J. DeFilippis, Readings in planning theory. John Wiley $\backslash \&$ Sons, 2015, doi: 10.1002/9781119084679.

[18] J. Forester, The deliberative practitioner: Encouraging participatory planning processes. Mit Press, 1999.

[19] K. Salen and E. Zimmerman, Rules of Play: Game Design Fundamentals. MIT Press, 2004.

[20] J. P. Zagal, J. Rick, and I. Hsi, "Collaborative Games: Lessons Learned from Board Games,” Simul. Gaming, vol. 37, no. 1, pp. 24-40, 2006, doi: 10.1177/1046878105282279.

[21] Y. Xu, E. Barba, I. Radu, M. Gandy, and B. Macintyre, "Chores Are Fun: Understanding Social Play in Board Games for Digital Tabletop Game Design," Proc. DiGRA 2011 Conf. Think Des. Play, 2011.

[22] M. J. Rogerson, M. R. Gibbs, and W. Smith, "Cooperating to compete: The mutuality of cooperation and competition in boardgame play," in Proceedings of the $2018 \mathrm{CHI}$ conference on human factors in computing systems, 2018, pp. 1-13, $10.1145 / 3173574.3173767$.

[23] M. J. Rogerson, M. Gibbs, and W. Smith, “'I Love All the Bits': The Materiality of Boardgames," in Proceedings of the 2016 CHI Conference on Human Factors in Computing Systems, 2016, pp. 3956-3969, doi: 10.1145/2858036.2858433.

[24] I. Mayer et al., "The research and evaluation of serious games: Toward a comprehensive methodology," Br. J. Educ. Technol., vol. 45, no. 3, pp. 502-527, 2014, doi: 10.1111/bjet.12067.

[25] L. C. Lederman, "Debriefing: Toward a Systematic Assessment of Theory and Practice," Simul. Gaming, vol. 23, no. 2, pp. 145-160, 1992, doi: 10.1177/1046878192232003.

[26] M. Sousa, "Modern Serious Board Games: modding games to teach and train civil engineering students," in 2020 IEEE Global Engineering Education Conference (EDUCON), 2020, pp. 197-201, 10.1109/EDUCON45650.2020.9125261.

[27] M. J. Rogerson and M. Gibbs, "Finding Time for Tabletop: Board Game Play and 
Parenting," Games Cult., vol. 13, no. 3, pp. 280-300, 2018, doi:

$10.1177 / 1555412016656324$.

[28] L. De Caluwé, J. Geurts, and W. J. Kleinlugtenbelt, "Gaming Research in Policy and Organization: An Assessment From the Netherlands," Simul. Gaming, vol. 43, no. 5, pp. 600-626, 2012, doi: 10.1177/1046878112439445.

[29] D. Crookall, "Serious Games, Debriefing, and Simulation/Gaming as a Discipline," Simul. Gaming, vol. 41, no. 6, pp. 898-920, 2010, doi: 10.1177/1046878110390784.

[30] M. Sousa and J. Dias, "From learning mechanics to tabletop mechanisms: modding steam board game to be a serious game," in 21 st annual European GAMEON@ Conference, GAME-ON®'2020, 2020.

[31] B. Schulz, "The importance of soft skills: Education beyond academic knowledge.," 2008.

[32] C. I. Johnson and R. E. Mayer, "Applying the self-explanation principle to multimedia learning in a computer-based game-like environment," Comput. Human Behav., vol. 26, no. 6, pp. 1246-1252, 2010, 10.1016/j.chb.2010.03.025.

[33] K. Charmaz, Constructing grounded theory. sage, 2014.

[34] L. Roubira, "Dixit." Libellud, 2008.

[34] Cutler, A and Fantastic, M., "Team3.” Brain Games, 2019.

[35] Lapp, K, “Magic Maze." Sit Down!, 2017.

[36] Användbart Litet Företag, "Telestrations.” Användbart Litet Företag, 2009.

[37] T. Fullerton, Game Design Workshop: A Playcentric Approach to Creating Innovative Games, 4th Editio. AK Peters/CRC Press, 2014, doi: 10.1201/b16671.

[38] B. Brathwaite and I. Schreiber, Challenges for game designers. Nelson Education, 2009. 


\section{Apendix}

\section{PRE-TEST}

\begin{tabular}{|l|c|c|c|c|c|}
\cline { 2 - 6 } \multicolumn{1}{c|}{} & \multicolumn{5}{c|}{ Likert scale of evaluation } \\
\cline { 2 - 6 } \multicolumn{1}{c|}{} & $\begin{array}{c}\text { Never } \\
(\mathbf{1})\end{array}$ & $\begin{array}{c}\text { At least once } \\
\text { per year } \\
(\mathbf{2})\end{array}$ & $\begin{array}{c}\text { At least once } \\
\text { per month } \\
\text { (3) }\end{array}$ & $\begin{array}{c}\text { At least once } \\
\text { per week } \\
\text { (4) }\end{array}$ & $\begin{array}{c}\text { Every day } \\
\text { (5) }\end{array}$ \\
\hline $\begin{array}{l}\text { How often do } \\
\text { you play games? }\end{array}$ & $\square$ & $\square$ & $\square$ & $\square$ & $\square$ \\
\hline
\end{tabular}

\begin{tabular}{|l|c|c|c|c|c|}
\cline { 2 - 6 } \multicolumn{1}{c|}{} & \multicolumn{6}{c|}{ Likert scale of evaluation } \\
\cline { 2 - 6 } \multicolumn{1}{c|}{} & \begin{tabular}{c} 
(None) \\
\multicolumn{1}{c|}{}
\end{tabular} & - & - & - & (Totally) \\
\hline Games are fun? & $\square$ & $\square$ & $\square$ & $\square$ & $\square$ \\
\hline $\begin{array}{l}\text { What is your current motivation to play } \\
\text { the proposed games? }\end{array}$ & $\square$ & $\square$ & $\square$ & $\square$ & $\square$ \\
\hline
\end{tabular}

\section{GAME INQUIRES (GI)}

Name of the game:

\begin{tabular}{|c|c|c|c|c|c|}
\hline \multirow{2}{*}{$\begin{array}{l}\text { Your feelings during } \\
\text { gameplay }\end{array}$} & \multicolumn{5}{|c|}{ Likert scale of evaluation } \\
\hline & $\begin{array}{c}\text { (None) } \\
1\end{array}$ & $\overline{2}$ & $\overline{3}$ & $\overline{4}$ & $\begin{array}{c}\text { (Totally) } \\
5\end{array}$ \\
\hline Fun & $\square$ & $\square$ & $\square$ & $\square$ & $\square$ \\
\hline Difficulty & $\square$ & $\square$ & $\square$ & $\square$ & $\square$ \\
\hline Engagement & $\square$ & $\square$ & $\square$ & $\square$ & $\square$ \\
\hline Challenge & $\square$ & $\square$ & $\square$ & $\square$ & $\square$ \\
\hline Anxiety & $\square$ & $\square$ & $\square$ & $\square$ & $\square$ \\
\hline Adaptation & $\square$ & $\square$ & $\square$ & $\square$ & $\square$ \\
\hline Surprise & $\square$ & $\square$ & $\square$ & $\square$ & $\square$ \\
\hline Frustration & $\square$ & $\square$ & $\square$ & $\square$ & $\square$ \\
\hline
\end{tabular}

\begin{tabular}{|c|c|c|c|c|c|}
\hline \multirow{2}{*}{$\begin{array}{l}\text { Other players feelings } \\
\text { during gameplay }\end{array}$} & \multicolumn{5}{|c|}{ Likert scale of evaluation } \\
\hline & $\begin{array}{c}\text { (None) } \\
1\end{array}$ & $\overline{2}$ & $\overline{\mathbf{3}}$ & $\overline{4}$ & $\begin{array}{c}\text { (Totally) } \\
5\end{array}$ \\
\hline Fun & $\square$ & $\square$ & $\square$ & $\square$ & $\square$ \\
\hline Difficulty & $\square$ & $\square$ & $\square$ & $\square$ & $\square$ \\
\hline Engagement & $\square$ & $\square$ & $\square$ & $\square$ & $\square$ \\
\hline Challenge & $\square$ & $\square$ & $\square$ & $\square$ & $\square$ \\
\hline Anxiety & $\square$ & $\square$ & $\square$ & $\square$ & $\square$ \\
\hline Adaptation & $\square$ & $\square$ & $\square$ & $\square$ & $\square$ \\
\hline Surprise & $\square$ & $\square$ & $\square$ & $\square$ & $\square$ \\
\hline Frustration & $\square$ & $\square$ & $\square$ & $\square$ & $\square$ \\
\hline
\end{tabular}

Describe the first words that came to your mind about this game experience: 


\section{POST-TEST}

\begin{tabular}{|l|c|c|c|c|c|}
\cline { 2 - 6 } \multicolumn{1}{c|}{} & \multicolumn{6}{c|}{ Likert scale of evaluation } \\
\cline { 2 - 6 } \multicolumn{1}{c|}{} & \begin{tabular}{c} 
(None) \\
\multicolumn{1}{c|}{}
\end{tabular} & $\mathbf{2}$ & $\mathbf{3}$ & $\mathbf{4}$ & (Totally) \\
\hline Games are fun? & $\square$ & $\square$ & $\square$ & $\square$ & $\square$ \\
\hline What is your current motivation level? & $\square$ & $\square$ & $\square$ & $\square$ & $\square$ \\
\hline $\begin{array}{l}\text { How do you classify the complexity of } \\
\text { the played games? }\end{array}$ & $\square$ & $\square$ & $\square$ & $\square$ & $\square$ \\
\hline $\begin{array}{l}\text { Where you engaged in the played } \\
\text { games? }\end{array}$ & $\square$ & $\square$ & $\square$ & $\square$ & $\square$ \\
\hline $\begin{array}{l}\text { How do you classify the level of } \\
\text { challenge of the played games? }\end{array}$ & $\square$ & $\square$ & $\square$ & $\square$ & $\square$ \\
\hline $\begin{array}{l}\text { How do you classify your level of } \\
\text { anxiety after playing the games? }\end{array}$ & $\square$ & $\square$ & $\square$ & $\square$ & $\square$ \\
\hline $\begin{array}{l}\text { How do you classify your level of } \\
\text { surprise after playing the games? }\end{array}$ & $\square$ & $\square$ & $\square$ & $\square$ & $\square$ \\
\hline $\begin{array}{l}\text { How do you classify your level of } \\
\text { frustration after playing the games? }\end{array}$ & $\square$ & $\square$ & $\square$ & $\square$ & $\square$ \\
\hline $\begin{array}{l}\text { Did the games achieved the objectives } \\
\text { previously defined for of the session? }\end{array}$ & $\square$ & $\square$ & $\square$ & $\square$ & $\square$ \\
\hline $\begin{array}{l}\text { Would you play these games just for } \\
\text { fun? }\end{array}$ & $\square$ & $\square$ & $\square$ & $\square$ & $\square$ \\
\hline
\end{tabular}

Final commentaries about the game session: 